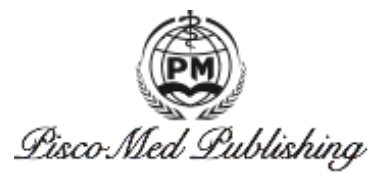

Original Research Article

\title{
Hydrogen Round Trip Efficiency
}

Chao Zheng*

De Montfort University, Leicester LE19BH, UK. E-mail: zchao2682@gmail.com

Abstract: The hydrogen economy is a glimpse into the future economic structure of energy. Hydrogen can be used as a power medium, and a typical way of using hydrogen is the round trip, defined as a process in which electricity becomes hydrogen and then returns to electricity form. The purpose of this paper is to briefly describe hydrogen round trip efficiency from production to releasing and find out the optimistic circumstances.

Keywords: Production Efficiency; Conversion Efficiency

\section{Introduction}

According to the IEA's (International Energy Agency) report, the transport sector is responsible for around $30 \%$ of the world's emissions, and it is composed of $70 \%$ emissions from on-road vehicles ${ }^{[1]}$. Hydrogen as a primary sustainable energy can be used in solving pollution. The key point in this problem is efficiency. The efficiency is divided into production and conversion efficiency. All current feasible methods of hydrogen production will be briefly outlined and experiment related to electrolysis to explore hydrogen round trip efficiency improvement will also be carried out. The research was conducted on small scale equipment, which includes a white hydrogen generator filled with pure water, a black fuel cell made of plastic with some metal mixture inside, a cylinder capturing and storing pure hydrogen which provided the source for the chemical reaction and a USB connected to a fan used for changing the condition of the output and cooling generated heat. All of these devices aim to simulate the process of producing hydrogen from electrolysed water. With a change in output current conditions, there should be variation in the output power and determine round trip efficiency. In this way, the parame- ters that maximise efficiency can be found in order to achieve optimum hydrogen energy use.

\section{Hydrogen round trip efficiency}

\subsection{Production efficiency}

There are many ways to produce hydrogen which related to two resources: fossil fuels and the renewable sources. There are three main ways to generate hydrogen. One is steam reforming using steam under the action of a catalyst. This reacts with the hydrocarbon cell, capturing carbon dioxide and storing it, outputting zero greenhouse emissions. It accounts for 80-85 percent hydrogen and it is the most cost-effective way. If we apply natural gas, the efficiency of this technology will be approximately $70 \%$. However, if we use some sources like methane, which contain sulphur or other impurities, the efficiency will be reduced because they need a pretreatment cleanup unit to purify the input fuel for the SMR process ${ }^{[2]}$. When fossil fuels are applied, the first step is to feed them into a purification system, which removes impurities like sulphide and increases efficiency. After purifying, the SMR process operating at 850 degrees (Celsius) can achieve 85 percent conversion efficiency. The efficiency

Copyright (C) 2020 Chao Zheng

doi: 10.18282/fme.v2i3.1272

This is an open-access article distributed under the terms of the Creative Commons Attribution Non-Commercial License

(http://creativecommons.org/licenses/by-nc/4.0/), which permits unrestricted non-commercial use, distribution, and reproduction in any medium, provided the original work is properly cited. 
can also be improved by burning the fuel exhaust, which will not penalise the energy directly and this is called the gas switching reform process. The experiment found that if the pressure dropped too low, the achievable H2 separation efficiency in the PSA unit reduced substantially, thus lowering the overall process efficiency. On the other hand, excessively high pressures limit the methane conversion in the GSR reactors with the same negative effect on process efficiency. An intermediate pressure of 25 bar was found to be optimal in this case ${ }^{[3]}$. The second source of hydrogen is electrolysis using electrolyte water to break down the association between the hydrogen and oxygen atom. It is important to note that the electricity for electrolysis comes from renewable green energy. An experiment was carried out to stimulate the process of the hydrogen round trip. Firstly, electricity is converted into hydrogen and this energy is stored as hydrogen. When energy is needed, it is released from the store and the round trip is calculated. There are two different types of hydrogen battery used in this experiment, whose code are 1007 and 0603. The charts are as follow:

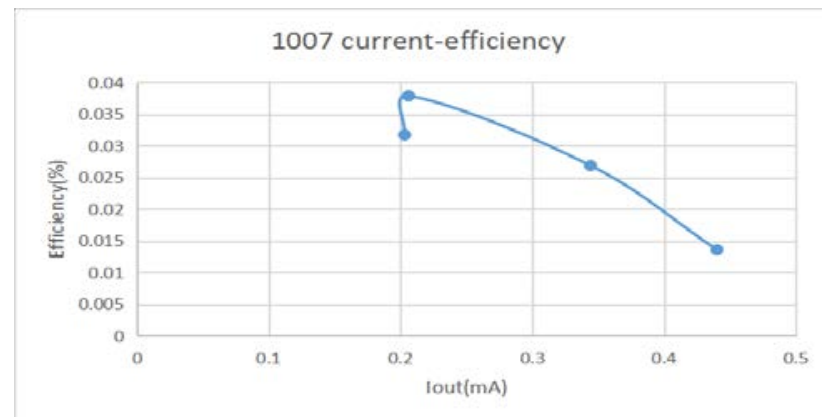

Figure 1. 1007 cylinder output current and efficiency.

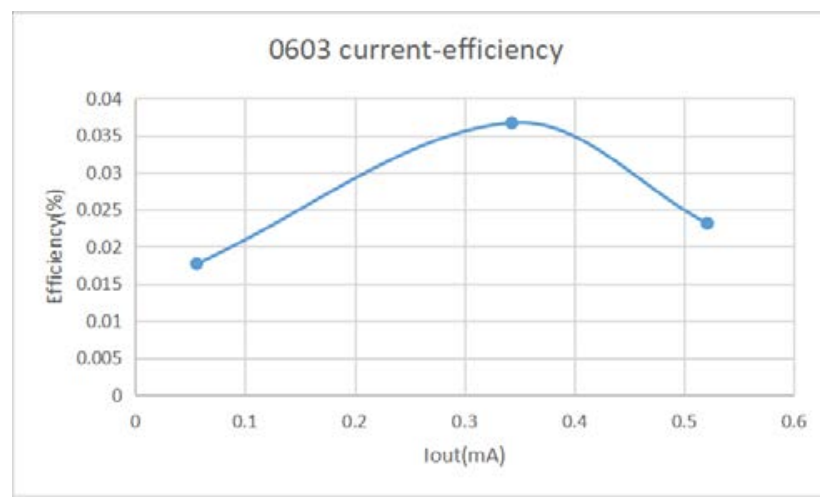

Figure 2. 0603 cylinder output current and efficiency.

As is shown, efficiency will change as output changes. The electrolysis efficiency is between three and five percent. The common point is that they can achieve the maximum conversion efficiency at a specific stable current output. Temperature also affects fuel cell performance; if the temperature is not in range or low, the output will be unstable. It is apparent that electrolysis is inefficient in these stages despite favourable electrolysis conditions. Efficiency can reach 80 percent and the overall efficiency of hydrogen generation has hugely improved. It is still not over $30 \%$ when taking transmission and other losses into account. Currently, electricity is not enough due to grid transportation, which can only trans- mit a fixed amount of energy. If technology advances, efficiency will be higher.

The last source is pyrolysis, where hydrocarbons will automatically decompose under high temperature and anaerobic conditions. Pyrolysis of biomass is one of the more promising methods for large-scale hydrogen production because it can use different energy sources to provide heat for the reaction such as biomass energy, methane and hydrogen sulphide. Temperature, residence time and type of catalyst are the most effective determining factors that control the yield of hydrogen production $^{[4]}$. The effect of temperature on the efficiency of hydrogen production is shown in the Figure 3. 


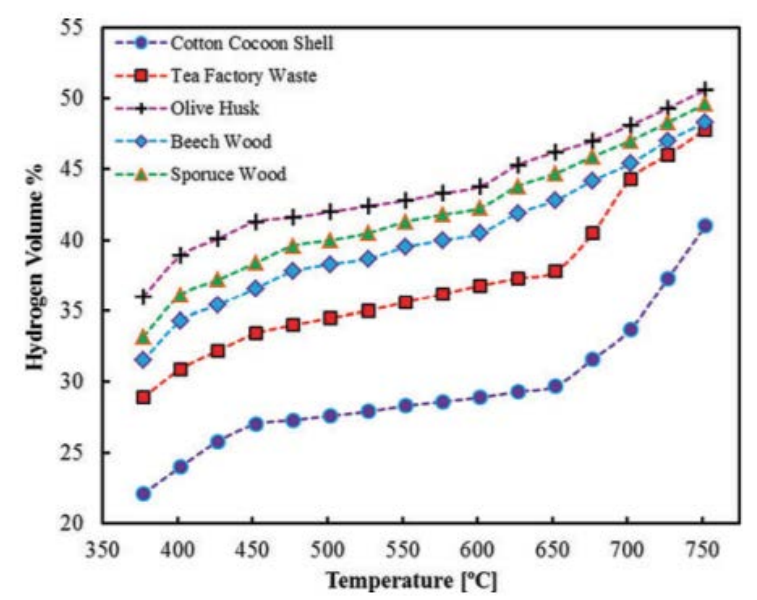

Figure 3. Relationship between temperature and efficiency.

As shown in the Figure 3, no matter what form of biomass energy is used, as the temperature rises, the hydrogen production will increase. It is also evident that different kinds of biomass energy affect efficiency and olive husk achieves the greatest efficiency in this experiment. The effect of residence time on the efficiency of hydrogen production is shown in the figure below.

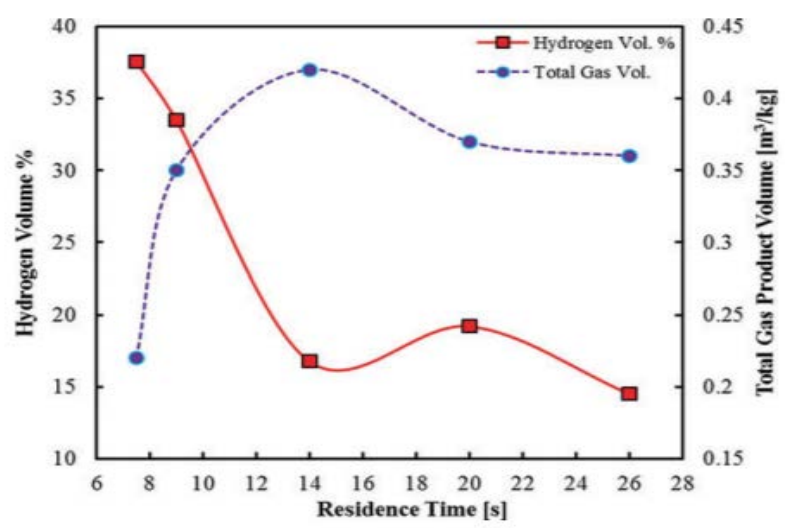

Figure 4. Relationship between residence time and efficiency.

Initially, hydrogen production decreases with increasing residence time; after it reaches a certain time, it starts to rise again and then decreases again after a fur- ther period of time. If the residence time is controlled at proper value, the maximum effect can be achieved.

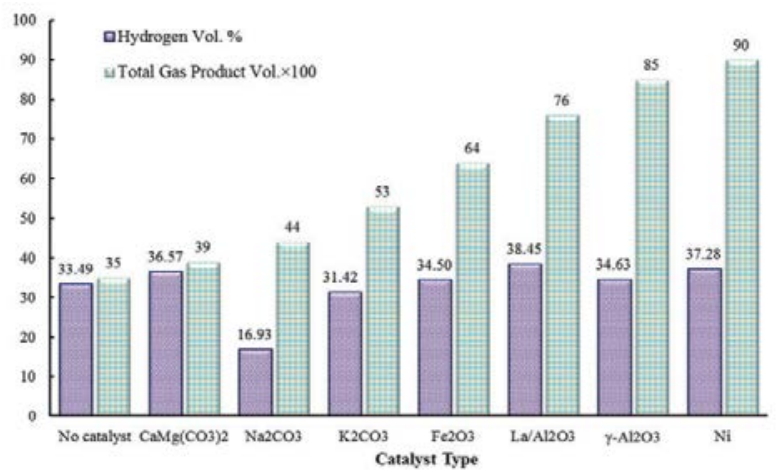

Figure 5. Relationship catalyst type and efficiency.

Almost all catalysts can increase hydrogen production, however, their effects are different. The Ni catalyst 
can increase hydrogen production by two and a half times, whereas, the effect of metal carbon oxide catalysts on production is relatively small. The effect of metal oxide catalyst on hydrogen is moderate.

\subsection{Conversion efficiency}

Now it should focus on the opposite efficiency, which converts hydrogen to other energy. With pure hydrogen as the input, fuel cells are at least $60 \%$ efficient at converting the stored energy in hydrogen into electricity. According to the different type of hydrogen fuel cells and different reactant temperatures, the efficiency will be different. For example, when reactant temperatures rise, the lowest value of the maximum efficiency is found to be $79.3 \%, 75.7 \%$, and $82.1 \%$ for hydrogen-oxygen, hydrogen-air and methane-air fuel cells ${ }^{[2]}$. Furthermore, this efficiency data can also be affected by different composition ratios; however their efficiency is close to 80 which is a high efficiency value that can be put into operation. In terms of hydrogen internal combustion engine efficiency, when the engine burns with hydrogen as fuel, its thermodynamic efficiency is between 20 and 25 percent, which is less efficient than fuel cells. The entire Otto process of a hydrogen internal combustion engine vehicle is similar to a traditional gasoline internal combustion engine vehicle. Its theoretical efficiency formula is demonstrated in Figure 2, which will be affected by the hydrogen and air mixing ratios at specific heats:

$$
\begin{aligned}
& \eta_{\mathrm{th}}=1-\frac{1}{\left(\frac{V_{1}}{V_{2}}\right)} \gamma-1 \\
& \text { where: } \\
& \mathrm{V}_{1} / \mathrm{V}_{2}=\text { the compression ratio } \\
& \gamma \quad=\text { ratio of specific heats } \\
& \eta_{\text {th }}=\text { theoretical thermodynamic efficiency }
\end{aligned}
$$

Figure 6. factors related to efficiency.

When mixing hydrogen with air, there will be a loss of power due to low energy content in a stoichiometric mixture. In reality, efficiency cannot reach as much as is necessary. The stoichiometric air/fuel ratio for hydrogen is 34:1. In this case, hydrogen occupies 29 percent of the combustion chamber and air occupies 71 percent. Fuel cell hydrogen vehicles only produce water, and thanks to advances in technology, fuel cells are designed to be the size of a pocket which means hydrogen fuel cells have a higher energy density. This reduces weight and increases overall efficiency. In terms of efficiency, hydrogen fuel cell vehicles have a brighter future than HICE.

Why not directly convert thermal energy into chemical energy? There is a thermoelectric generator that uses temperature difference to convert thermal energy to electric energy, however, the efficiency of this process is between $5 \%$ and $8 \%$, therefore it cannot be used for large-scale production work.

\section{Discussion and conclusion}

In order to achieve all-electricity, it is important to hydrogen energy is an essential key factor. At this stage,
SMR is the only way to produce a large amount of hydrogen as the same with high efficiency. Pyrolysis is an auxiliary method to produce a small amount of hydrogen. Electrolysed water is needed and it is expected it will become the mainstream hydrogen production method in the future. Because electricity can be derived from renewable energy and it is sustainable and pollution-free. With the advancement of technology, it has been able to reach $80 \%$ efficiency in hydrogen production. As regard to conversion efficiency, hydrogen internal engine is more related to compress ratio of hydrogen and air, fuel cell hydrogen vehicle will rely more on different type of hydrogen fuel cells, different reactant temperatures and light body.

In the future, hydrogen cars may become mainstream because of technological advances and their pollution-free nature due to the fact that there are no recycling requirements. At this stage, hydrogen is mainly produced through the combustion of fossil fuels, and its efficiency is low. In future, hydrogen is expected to achieve greater efficiency through electrolysed water. There are still many deficiencies and decarbonisation is 
necessary for progression, especially in the case of pollution-free cars. Future research should mainly focus on finding methods that can be used for large-scale and efficient production and conversion.

\section{References}

1. Tanç B, Arat H, Baltacioğlu E, et al. Overview of the next quarter century vision of hydrogen fuel cell electric vehicles. International Journal of Hydrogen Energy 2019; 44(20): 10120-10128.

2. Hamdi A, Ramtin RN, Mohammad S. Distributed generation systems design, operation and grid integration. Oxford, United Kingdom; Cambridge, MA.: Butterworth-Heinemann, an imprint of Elsevier; 2017. p. 221-300.

3. Nazir S, Cloete J, Cloete S, et al. Efficient hydrogen production with $\mathrm{CO} 2$ capture using gas switching reforming. Energy 2019; 185: 372-385.

4. Bakhtyari A, Makarem MA, Rahimpour MR. Hydrogen production through pyrolysis [Internet]. Link.springer.com.; 2020 [cited 2020 Mar 16]. Available from: https://link.springer.com/content/pdf /10.1007\%2F978-1-4939-2493-6_956-1.pdf. 